\title{
Static contact angle measurement at different volumes of a drop sitting on non-ferrous metals
}

\author{
Dmitriy Feoktistov ${ }^{1,2}$, Evgeniya Orlova1, a , Kseniya Batischeva ${ }^{1}$ and Andrey Semenov² \\ ${ }^{1}$ National Research Tomsk Polytechnic University, 30, Lenin Ave, 634050, Tomsk, Russia \\ ${ }^{2}$ Institute of Thermophysics SB RAS, 1, Lavrentiev Ave, 63090, Novosibirsk, Russia
}

\begin{abstract}
The paper presents the experimental study of the effect of the liquid volume on the static contact angle under the condition of the stationary contact line on the rough and polished surfaces of non-ferrous metals. The experiments were carried out using the shadow optical system. Comparison between two methods of drop profile processing was conducted. It was found that in addition to the friction and gravity forces, the structure of the non-ferrous metals significantly influence on the static contact angle during changing the drop volume.
\end{abstract}

\section{Introduction}

A contact angle is an inclination of the liquid surface to the wetted solid surface $[1,2]$. There is an equilibrium contact angle, which depends only on the thermodynamic properties of the gas-liquidsolid system and non-equilibrium contact angle. This non-equilibrium contact angle is measured when the system deviates from the equilibrium. The non-equilibrium contact angles, corresponding to the constant wetted surface, are called static angles.

It is known [1] that the static contact angle depends on the drop volume if there are some physicochemical processes (evaporation, dissolution of a solid body in liquid, adsorption, chemical reactions). In their absence, the static angle is independent of volume.

In recent years, the solid surfaces with a chemical or topographic patterning attract much attention due to their potential use in the production of the electronic components, micro-channels, micro-scale cooling systems, as well as the development of self-cleaning, anti-fogging, anti-bacterial surfaces [36]. Studies in this field are carried out as a search of a specific geometric configuration of the microstructure, improving hydrophobic or hydrophilic properties [7-10]. At the same time, the fundamental laws of the processes, when the static angle forms on the structured surfaces have not been studied for predictive modelling.

The aim of this work was to determine experimentally the effect of a drop volume on the value of the contact angle under the condition of stationary three-phase contact line in the wetting of the nonferrous metals.

\footnotetext{
${ }^{\text {a }}$ Corresponding author : lafleur@tpu.ru
} 


\section{Experimental}

The experimental study was carried out on the setup [11, 12], including the shadow optical system [4, 11-13].

A drop with a set volume was placed on the surface by an electronic dosing device Single Channel Pipette (Thermo Scientific). A drop profile was obtained by the shadow optical system, which consists of the camera (NIKON D7100) equipped with a macrolens (Nikon 105mm f/2.8G IF-ED AF-S), and the source of the plane-parallel light (MI-150 Edmund). The contact angle was obtained after processing the images in the software Drop Shape Analyses (DSA) by two methods (tangential 1, Young-Laplace). $1)$.

According to results of preliminary experiments the range of input parameters was defined (Table

Table 1. Input parameters of the experimental research

\begin{tabular}{|c|c|}
\hline Liquid under the study & nondeaerated distilled water \\
\hline Material of substrate & aluminium, copper, brass \\
\hline Volume of liquid & $10,20,30,40,50,60 \mu \mathrm{l}$ \\
\hline
\end{tabular}

The metal surfaces was analysed on the profilometer "Micro Measure 3D station" and microscope Hitachi TM-3000. The parameter of roughness (arithmetic average roughness) and microstructure were defined for substrates under investigation (Table 2).

Six substrates were used in the present study made of aluminium, copper and brass. The surfaces of three substrates were rough. The roughness was formed by longitudinally arranged grooves. And the others were processed on grinding machine with diamond grit (polished surfaces).

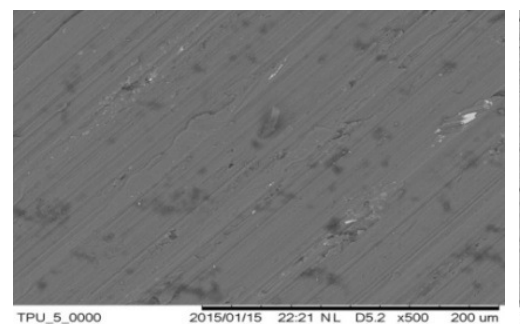

(a)

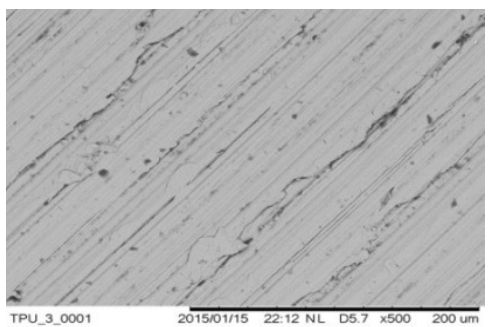

(b)

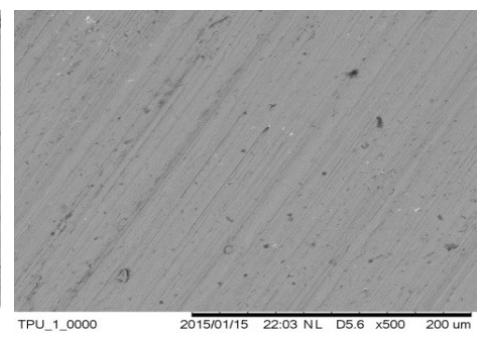

(c)

Figure 1. Microstructure of the rough substrates with magnification $\times 500$ : (a) aluminium $(\operatorname{Ra}=0.374 \mu \mathrm{m})$; $(\mathrm{b})$ copper $(\mathrm{Ra}=0.361 \mu \mathrm{m})$; (c) brass $(\mathrm{Ra}=0.939 \mu \mathrm{m})$.

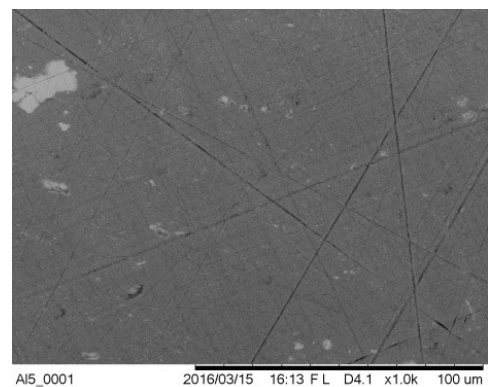

(a)

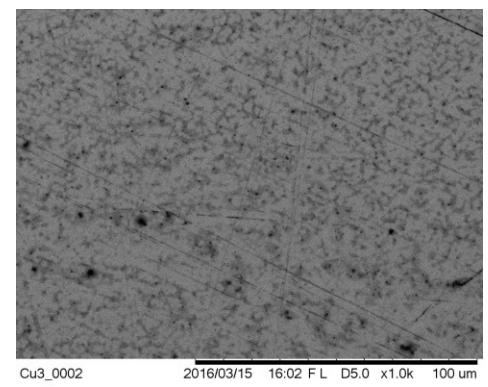

(b)

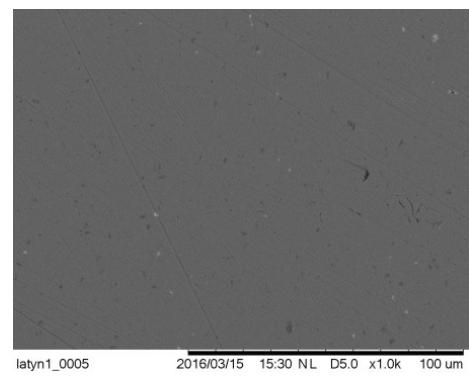

(c)

Figure 2. Microstructure of polished substrates with magnification $\times 1000$ : (a) aluminium $(\mathrm{Ra}=0.036 \mu \mathrm{m})$; (b) copper $(\mathrm{Ra}=0.024 \mu \mathrm{m})$; (c) brass $(\mathrm{Ra}=0.032 \mu \mathrm{m})$. 


\section{Results and discussion}

According to results of the experiments the dependences of the contact angle from the drop volume were obtained (Figure 3).

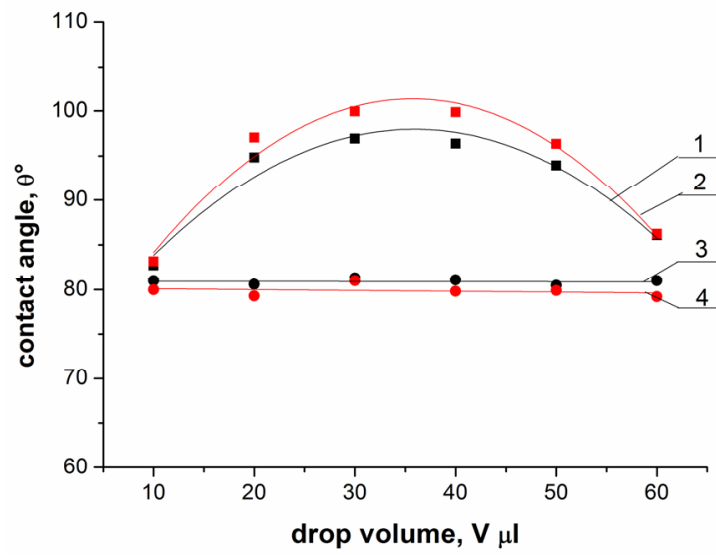

(a) Brass

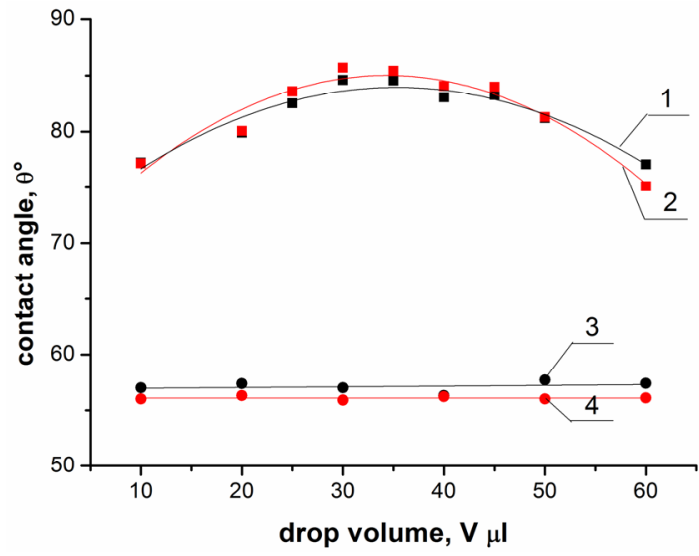

(b) Copper

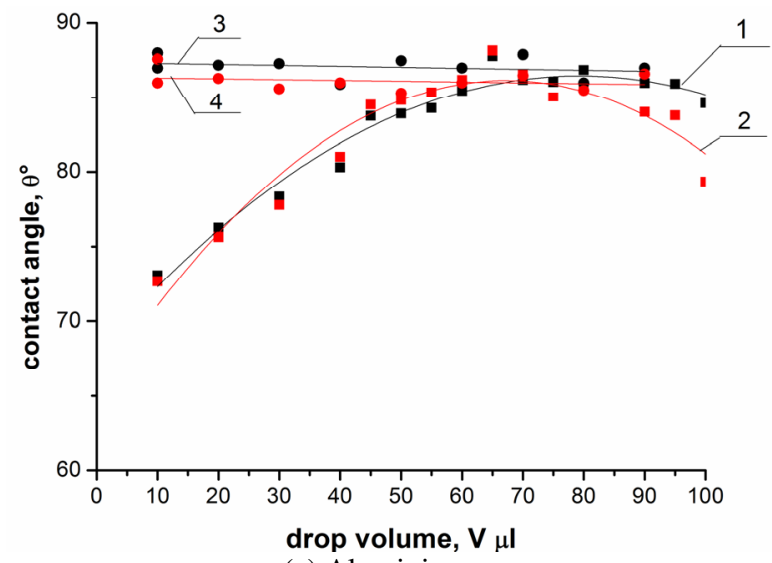

(c) Aluminium

Figure 3. Static contact angle versus drop volume on substrates unpolished and polished surfaces. The results were obtained by two methods of processing: 1 - tangential 1 method, unpolished substrate; 2 - Young-Laplace method, unpolished substrate; 3 - tangential 1 method, polished substrate; 4 - Young-Laplace method, polished substrate.

According to analyses of the results (Figure 3) it was found that the dependence of the contact angle from the drop volume on the surface with longitudinally arranged grooves can be fitted by parabolic curve with branches directed downwards (lines 1 and 2). The static contact angle does not depend on the drop volume on polished surfaces (lines 3 and 4).

The experimental data (Figure 1) are processed by the method of least squares. According to the first derivative of the polynomial dependence of the second order the maximum value $\left(\theta_{\max }\right)$ and the corresponding drop volumes (V) were determined. Results of computations are presented in Table 2.

The maximum divergence of $\theta_{\max }$ obtaining by Young-Laplace and tangential methods was $17 \%$ for the aluminium substrate. For copper and brass this value was not more than $4 \%$. Probably, it is due to the most highly reflective surface of the aluminium substrate as compared to other non-ferrous metals used in the experiments. 
Table 2. Computational results of the contact angle and the volume of the drop

\begin{tabular}{|c|c|c|c|c|}
\hline \multirow{2}{*}{ Unpolished substrates } & \multicolumn{2}{|c|}{ Young-Laplace method } & \multicolumn{2}{c|}{ Tangential 1 method } \\
\cline { 2 - 5 } & $\theta_{\max },{ }^{\circ}$ & $\mathrm{V}, \mu \mathrm{l}$ & $\theta_{\max }{ }^{\circ}$ & $\mathrm{V}, \mu \mathrm{l}$ \\
\hline Aluminium & 86.2 & 67.4 & 104.2 & 78.0 \\
\hline Copper & 85.0 & 34.3 & 84.0 & 35.5 \\
\hline Brass & 101.3 & 35.7 & 97.9 & 35.8 \\
\hline
\end{tabular}

It should be noted, that the shape of the drop (its symmetry) was controlled by the optical system. The drop has a shape of a spherical segment in all experiments.

Difference in the nature of the obtained dependences may be explained as follows. During increasing the drop the influence of the friction and gravity forces on the static contact angle increases. In addition to these forces, the microstructure has a significant influence. Two states of a drop wetting the solid patterned substrates are known [14-16]: Cassie-Baxter state and Wenzel state. It may be assumed, that at relatively small volumes of drops liquid on the structured surface is placed on an "air cushion" $[14,15]$. The weight of a drop is small; the liquid does not fill the microasperities. When the volume increases, the drop may transit to the Wenzel state due to the gravity (because of increasing the weight). It is possible that the maximum value of the contact angle on structured surfaces (Figure 1) corresponds to the transition from the Cassie-Baxter State to the Wenzel State.

The roughness $(\mathrm{Ra})$ of the polished surfaces is relatively small and does not exceed $0.036 \mu \mathrm{m}$. Microasperities and microcavities do not affect the static contact angle.

\section{Conclusion}

The effect of the volume on the contact angle of a drop was studied under the conditions of stationary contact line on the rough and polished surfaces of non-ferrous metals. The comparison between two methods of drop profile processing was carried out. It was found that the maximum divergence of $\theta_{\max }$ obtaining by Young-Laplace and tangential methods was $17 \%$ for the aluminium substrate. For copper and brass this value was not more than $4 \%$. Probably, it is due to the most highly reflective surface of the aluminium substrate as compared to other non-ferrous metals, used in the experiments. It was found that in addition to the friction and gravity forces, the structure of the non-ferrous metals significantly influence on the static contact angle during changing the drop volume.

The work was realized within the research state assignment “Science” №13.1339.2014/K (Code of Federal Target Scientific and Technical Program 2.1410.2014). The shadow optical system was elaborated under the support of Russian Science Foundation (Agreement No. 14-19-01755).

\section{References}

1.B.D Summ, Yu.V. Goryunov, The Physochemical Principles of Wetting and Spreading [in Russian] (Khimiya, Moscow, 1976)

2.P.G. de Gennes, Rev. Mod. Phys. 57, 827 (1985)

3.V.S. Ajaev, E.Ya. Gatapova, O.A. Kabov, Adv. Colloid Interface Sci. 228, 92 (2016)

4.E.Ya. Gatapova, A.A. Semenov, D.V. Zaitsev, O.A. Kabov, Colloids and Surfaces A 441, 776 (2014)

5.V.S. Ajaev, E.Ya. Gatapova, O.A. Kabov, Phys Rev E 84, 041606 (2011) 
6. R. Blossey, Nat Mater 2, 301 (2003)

7.V.E. Nakoryakov, S.L. Elistratov, S.Ya. Misyura, Journal of Engineering Thermophysics 20, 1 (2011)

8.E. Nakoryakov, S.Ya. Misyura, S.L. Elistratov, Int J Heat Mass Tran 55, 6609 (2012)

9.Z.-G. Guo, W.-M. Liu, Appl Phys Lett 90, 223111 (2007)

10. V. Hejazi, K. Sobolev, M. Nosonovsky, Sci Rep 3, 2194 (2013)

11. E.G. Orlova, G. V. Kuznetsov, D. V. Feoktistov, EPJ Web of Conferences 82, 01053 (2015)

12. D. Feoktistov, E. Orlova, A. Islamova, EPJ Web of Conferences 110, 01018 (2016)

13. O.A. Kabov, D.V. Zaitsev, Doklady Physics 58, 292 (2013)

14. A.L. Dubov, A. Mourran, M. Möller, O.I. Vinogradova, Appl Phys Lett 106, 241601 (2015)

15. A.L. Dubov, A. Mourran, M. Möller, O.I. Vinogradova, J Phys Chem 141, 074710 (2014)

16. O.I. Vinogradova, A.V. Belyaev, J Phys Condens Matt 23, 184104 (2011) 